\title{
BERLIM: GUERRA, MEMÓRIA E INCLUSÃO
}

\author{
Prof. Dr. Marcos Horácio Gomes Dias ${ }^{8}$
}

\section{RESUMO}

O objetivo deste artigo é contextualizar o surgimento de museus e memoriais em Berlim após a II Guerra Mundial, principalmente após a queda do muro, marcado pela memória das vítimas e daqueles que sofreram as consequências das guerras e das divisões internas. Este artigo pretende fazer uma intepretação de alguns desses espaços berlinenses tentando, sobretudo, entender como a memória e a inclusão da História no espaço urbano é possível mesmo quando não temos mais vestígios concretos desse mesmo passado. Serve também para pensarmos quais as escolhas que foram feitas nesse resgate, quais as memórias e os grupos que foram privilegiados.

PALAVRAS-CHAVE: Berlim; Museu; Memorial; Monumento; Inclusão; História Contemporânea.

\begin{abstract}
The objective of this article is regarding the context of the appearance of museums and memorials in Berlin after World War II, especially after the fall of the Berlin Wall, marked by the memory of the victims and those who suffered the consequences of wars and internal divisions. This article intends to interpret some of these Berlin spaces, trying, above all, to understand how the memory and inclusion of History in urban space is possible even when we have no more concrete vestiges of this past. It also serves to think about the choices that were made in this rescue, which memories and groups that were privileged.
\end{abstract} KEY-WORDS: Berlin; Museum; Memorial; Monument; Inclusion; Contemporary history

\section{INTRODUÇÃO}

Berlim é a capital da República Federal da Alemanha e sua cidade mais populosa, formando o centro da região metropolitana de Berlim / Brandemburgo. Documentada pela primeira vez no século XIII, Berlim sempre esteve no curso da história da Europa central, sediando vários palácios e residências governamentais da região de Brandemburgo, da Prússia e do Reich alemão. No século XIX, tornou-se um importante centro industrial e, por causa do próprio desenvolvimento econômico e da criação da

\footnotetext{
${ }^{8}$ Doutor em História pela Pontifícia Universidade Católica de São Paulo (PUC-2012), possui mestrado em História Social pela Universidade de São Paulo (USP-2000), pós-gradução em Arte e Cultura Barroca pela Universidade Federal de Ouro Preto (UFOP-1999) e graduação em Ciências Sociais pela Universidade de São Paulo (USP-1995). Atualmente é professor do Museu de Arte Sacra de São Paulo (MAS), da Universidade São Judas Tadeu (USJT) e do Centro Universitário Assunção (Unifai).
}

Revista Lumen, v. 4, $\mathrm{n}^{\circ}$ 7, Jan./Jun. - 2019 - ISSN: 2447-8717 
Alemanha como um Estado unificado, viu-se envolvida em duas grandes guerras, sendo devastada pela segunda e dividida após a rendição do governo Nacional Socialista.

Berlim foi a cidade mais bombardeada da história. Durante a Segunda Guerra Mundial, grandes partes de Berlim foram destruídas nos ataques aéreos de 1943-45 e durante a Batalha de Berlim. Os aliados lançaram toneladas de bombas na cidade, destruindo muitos acres de área construída e matando milhares de civis. Os poderes vitoriosos dividiram a cidade em quatro setores, análogos às zonas de ocupação nas quais a Alemanha estava dividida. Os setores dos aliados ocidentais (Estados Unidos, Reino Unido e França) formaram a Berlim Ocidental, enquanto o setor soviético formou Berlim Oriental.

Após o fim da guerra na Europa, em maio de 1945, Berlim recebeu um grande número de refugiados das províncias orientais e, com a reunificação alemã no ano de 1990, tornou-se novamente a capital política da nação, da sede do governo federal e da presidência federal, bem como de numerosos ministérios federais e embaixadas. A cidade se viu como um importante centro europeu de indústrias e comércio, de setores da tecnologia da informação e do tráfego ferroviário e aéreo.

Toda essa história, condensada em um único espaço, é um convite para percebemos suas várias faces, suas várias fases, suas construções e suas reconstruções e, sobretudo, a luta para a construção de uma memória que leva em consideração os horrores da guerra e, principalmente, faz um acerto de contas com as potências vencedoras do ocidente. Hoje é uma cidade povoada de monumentos, museus, edifícios públicos e religiosos que revelam um centro cosmopolita e que reabilitam a História em um centro urbano moderno povoado pelas inovações da arquitetura do século XX e XXI.

Uma das maiores características dessa reabilitação refere-se principalmente às reconstruções constantes, o que gera sempre um debate no mundo acadêmico e intelectual. Os especialistas têm medo da falsificação da História ao exporem edifícios que não seriam mais testemunho do passado. ${ }^{9}$

A maneira como a cidade de Berlim resgata a memória aponta para um discurso de reconhecimento dos desvios do passado e o registo de uma Alemanha que se diz democrática, inclusiva e afinada com os valores do mundo contemporâneo. Esses marcos, notabilizados pelos aparelhos culturais que povoam a cidade, coadunam-se perfeitamente com a imagem de uma das nações mais ricas do planeta e que exerce, finalmente, um papel há muito almejado de preponderância dentro do universo político europeu.

Berlim sempre foi pensada na sua modernidade: “(...) a maioria dos interessados na cultura do século XX (...) identificou [que] a identidade de Berlim estava inexplicavelmente ligada ao Modernismo Internacional e ao metropolitanismo da República de Weimar. As vastas urbanizações modernistas, as montras iluminadas nas Friedrichstrasse e Leipzigerstrasse, os primeiros semáforos europeus em Potsdamer Platz, as vibrantes unidades fabris, o ritmo do sistema moderno de metropolitano e de ligações suburbanas e o influxo contínuo de pessoas nas concorridas estações ferroviárias compreendiam a paisagem física de Berlim metropolitana (...)”. (RALPH, 2008. p. 118).

${ }^{9}$ BENJAMIN, 2012, p.19-23

Revista Lumen, v. 4, n 7, Jan./Jun. - 2019 - ISSN: 2447-8717 
Este artigo pretende fazer uma intepretação de alguns desses espaços berlinenses tentando, sobretudo, entender como a memória e a inclusão da História no espaço urbano é possível mesmo quando não temos mais vestígios concretos desse mesmo passado. Serve também para pensarmos quais as escolhas que foram feitas nesse resgate, quais as memórias e os grupos que foram privilegiados e ajuda-nos, sobretudo, a pensar como as políticas públicas de países como o Brasil ainda não entenderam seu patrimônio histórico-cultural como formador de identidade e de inclusão dos mais diversos grupos que compõem sua história.

\section{EAST SIDE GALLERY: PEDAÇOS ARTÍSTICOS DA MEMÓRIA}

A East Side Gallery é uma grande galeria de arte ao ar livre que ocupa o espaço correspondente a um dos trechos do antigo Muro de Berlim. Esse espaço tem a pretensão de guardar, resguardar e ser ocupado com pinturas, grafites e pichações que remetam ao passado de divisão da cidade entre Berlim Oriental e Berlim Ocidental. A galeria também é aberta para composições de artistas contemporâneos que apresentem temáticas ecológicas, humanistas e pacifistas. Já muito comentada durante o período da Guerra Fria, mesmo não tendo esse nome, significou sempre um lugar de expressão da juventude berlinense contra $o$ status quo do período. Essa parte pintada e elaborada artisticamente ocorria apenas no lado ocidental, já que o lado oriental era fortemente vigiado pela patrulha de fronteira. Cenas como o beijo, pintado por Dmitri Vrubel, mostravam Brezhnev, Secretário Geral do Partido Comunista Soviético, tocando os lábios de Honecker, então Presidente da Alemanha Oriental. Seria a própria representação de união entre os dois países do bloco socialista

Hoje, a East Side Gallery é um concorrido lugar de turismo e de manifestações artísticas e partidárias. Sua função maior é ser um memorial de um período especifico da história da cidade: a Guerra Fria. Seu cenário é lembrando constantemente por produções cinematográficas, instalações artísticas, shows de rock, etc. Sua presença nos recorda que o Muro de Berlim foi um sistema de fortificação hermético que separou e demarcou de maneira definitiva as fronteiras entre República Federal Alemã (RFA) e a República Democrática Alemã (RDA) no espaço urbano da cidade por mais de 28 anos (de 13 de agosto de 1961 a 9 de novembro de 1989). Ele separou não só a Grande Berlim entre as áreas de influência capitalista ocidental e o socialismo oriental, como interrompeu as conexões e a circulação de pessoas entre esses dois polos. Por causa disso, foi o maior símbolo da fronteira entre esses dois mundos durante o período da Guerra Fria. ${ }^{10}$

\footnotetext{
${ }^{10} \mathrm{O}$ exemplo maior dessa situação é a existência, ainda, de estações fantasmas na viária do metrô. A construção do Muro de Berlim foi tão surpreendente para o governo responsável por Berlim Ocidental que pode ser exemplificada pelas atitudes cotidianas do momento: À noite, os trens do metrô estacionaram. No dia seguinte, com a construção da muralha, os trilhos ferroviários foram bloqueados, de modo que os trens não puderam se mover, já que não havia outras conexões possíveis. Os trechos separados das pistas tiveram que ser usados novamente por um curto período durante o dia, para que os trens pudessem ser transferidos para Berlim Ocidental que, a partir desse momento, precisaria repensar seu transporte urbano.
} 
Com o fim da Segunda Guerra Mundial, todos os quatro Aliados compartilhavam responsabilidades administrativas em Berlim e os conflitos aí inerentes resultaram na construção dessa fortificação que dividiu a cidade por décadas.

\begin{abstract}
Depois da II Guerra Mundial, ainda houve uma certa esperança de que a Grã-Bretanha pudesse encarregar-se de razoável parcela das responsabilidades pela manutenção da ordem mundial, e era geral a expectativa de que as Nações Unidas ajudassem a preservar a paz. Mas logo se viu que a retirada americana seria praticamente equivalente a consentir que a maior parte ou toda a Europa e o resto do mundo caíssem sob a hegemonia da União Soviética (...) (WESSON, 1978, p. 28).
\end{abstract}

Já em 1948, quando os aliados ocidentais estenderam uma reforma monetária a todas as zonas ocidentais da Alemanha, a União Soviética impôs um bloqueio às rotas de acesso para Berlim Ocidental, que ficava inteiramente dentro das fronteiras controladas pelos soviéticos. O transporte aéreo de Berlim, conduzido pelos três aliados ocidentais, superou esse bloqueio, fornecendo alimentos e outros suprimentos para a cidade. Em 1949, a República Federal da Alemanha foi fundada na Alemanha Ocidental e incluía todas as zonas americanas, britânicas e francesas. Ao mesmo tempo, a República Democrática Alemã, de inspiração marxista-leninista, era proclamada na Alemanha Oriental. A cidade de Berlim encontrava-se assim no centro dos problemas e das rivalidades criadas pelos blocos capitalista e socialista. Berlim Ocidental permanecia oficialmente como uma cidade ocupada, mas politicamente estava alinhada com a República Federal da Alemanha, apesar do isolamento geográfico que sofria dos seus pares. Berlim Ocidental estava cercada pelo território da Alemanha socialista e a Alemanha Oriental proclamava a parte oriental de Berlim como sua capital, local onde estava a maior parte do centro histórico da cidade. Dessa maneira, o governo da Alemanha Ocidental estabeleceu-se em Bonn.

Em 1961, a Alemanha Oriental começou a construir um muro ao redor de Berlim Ocidental e as tensões aumentaram constantemente até gerar um impasse entre tanques de guerra em umas das passagens conhecida como Checkpoint Charlie. Berlim Ocidental era nesse momento, de fato, uma parte da Alemanha Ocidental com um status legal único, enquanto Berlim Oriental era de fato parte da Alemanha Oriental socialista sob a influência soviética. Berlim estava completamente dividida. Embora fosse possível para os ocidentais passarem para o outro lado através de postos de controle estritamente controlados, a maioria dos orientais não podiam viajar para Berlim Ocidental ou para a Alemanha Ocidental. O serviço de linha aérea para Berlim Ocidental, vindo dos países ocidentais, por exemplo, foi concedido apenas às companhias aéreas americanas, britânicas e francesas. Como parte do apoio ocidental à Berlim, John F. Kennedy fez seu discurso "Ich bin ein Berliner" em 1963, destacando o apoio dos EUA à parte ocidental da cidade. Em 1971, um acordo garantiu o acesso a Berlim Ocidental de carro ou trem pela Alemanha Oriental.

Para os guardas de fronteira da Alemanha Oriental, era permitido o disparo com arma de fogo para impedir qualquer avanço da fronteira. Isto era considerado uma medida extrema. De qualquer forma, era 
proibido o uso de arma de fogo antes de feriados ou visitas de Estado para evitar uma imagem negativa diante da imprensa ocidental. A partir do lado ocidental, a fronteira era vigiada pela polícia de Berlim Ocidental e pela coalizão das forças militares aliadas. Mais tarde, descobriu-se ainda que existiam passagens ocultas que eram usadas pelas forças dos dois lados.

A fronteira externa da cidade de Berlim Ocidental tinha, ao mesmo tempo, várias áreas de águas navegáveis. A fronteira era caracterizada por uma corrente de boias brancas redondas, erguidas pelo governo com a inscrição "Sektorgrenze" (não aplicável nos limites da cidade). As embarcações de recreio e os navios de passageiros de Berlim Ocidental tinham que tomar cuidado para se manterem ao lado oeste da cadeia de boias. Em alguns lugares do Rio Spree, havia barreiras submersas contra nadadores. Para os refugiados, não ficava claro quando atingiam o território ocidental, de modo que, mesmo depois de terem superado a linha real, corriam o risco de serem capturados.

Em 1989, com o enfraquecimento da Guerra Fria e a pressão da população da Alemanha Oriental, o Muro de Berlim caiu no dia 9 de novembro e foi subsequentemente demolido em sua maior parte. Nas primeiras semanas, as tropas de fronteira tentavam de alguma maneira manter alguma patrulha em toda a extensão do muro, mas novas passagens eram abertas; incluindo algumas em lugares particularmente emblemáticos como Potsdamer Platz, Glienicker Bridge e Bernauer Strasse. Multidões se reuniam nessas passagens, esperando pela abertura e vibrando por cada pedaço de concreto que era levantado. A guarda do muro tornou-se cada vez mais tolerante ao longo do tempo e o cruzamento descontrolado pela fronteira era cada vez mais ignorado. Os guardas faziam apenas verificações aleatórias do fluxo do tráfego. A abertura da parede no Portão de Brandemburgo ocorreu oficialmente em 22 de dezembro, na presença do Chanceler Federal e do Primeiro Ministro da RDA.

Em $1^{\circ}$ de julho de 1990 , entrada em vigor da união monetária, a guarda do muro e todos os controles de fronteira foram interrompidos. A demolição do muro interior da cidade, por sua vez, terminaria oficialmente apenas em novembro de 1990. A partir de então, segundo estimativas da tropa de fronteira, tiveram que controlar milhões de toneladas de escombros. O que restou foram seis seções que deveriam ser preservadas como um memorial. Nesse momento, segmentos do muro pintados e grafitados já estavam sendo vendidos em grandes casas de leilões.

Alguns dos fragmentos do muro podem ser encontrados hoje em diferentes partes do mundo. A CIA, o serviço secreto dos EUA, assegurou para seu novo edifício em Langley (Virgínia), alguns desses fragmentos. Nos Jardins do Vaticano, em agosto de 1994, foram erguidos pedaços com a pintura da Igreja de São Miguel. Outra parte do muro pode ser visitada na Casa da História em Bonn. Um segmento está em Munique e outros fragmentos estão no Museu da Paz em Caen, na França, e no Imperial War Museum, em Londres.

A queda do Muro de Berlim marcou o fim de uma época e a queda da metáfora mais importante do momento: a "Cortina de Ferro". Sua queda possibilitou a reunificação da Alemanha que ocorreria em 3 de outubro de 1990. Em seguida, o Parlamento alemão votou a transferência da sede da capital de Bonn 
para Berlim - ato que foi totalmente concretizado em 1999. Em 18 de junho de 1994, soldados dos Estados Unidos, França e Grã-Bretanha marcharam juntos pela última vez em um desfile que marcava a retirada final das tropas estrangeiras do solo da cidade.

A partir desse momento, estabeleceu-se uma discussão sobre o que fazer em relação ao antigo caminho que o muro percorria dentro da cidade e como torná-lo visível na paisagem urbana. Entre várias propostas, estava aquela que pensava em manter uma fila dupla de pedras na pavimentação correspondente ao antigo percurso. Outras pediam uma faixa de bronze embutida no revestimento do piso, marcações por diferentes listras coloridas, etc. Todas essas variantes foram executadas para fins ilustrativos. Como resultado dessa discussão, especialmente na área do centro da cidade, cerca de oito quilômetros do percurso de muro foram marcados por uma linha dupla de pedras na pavimentação. Em intervalos irregulares, ao lado da antiga Berlim Ocidental, faixas de bronze permitem que o transeunte leia: "Muro de Berlim 1961-1989".

Hoje, o trecho mais conhecido é aquele chamado de East Side Gallery, que se tornou uma exposição de arte ao ar livre com obras que estão diretamente pintadas e representadas nas paredes existentes. Serve como memorial dos momentos mais dramáticos vividos pela cidade durante a Guerra Fria e é a maior evidência remanescente da divisão histórica da cidade.

\section{BERNAUER STRASSE, TORRES DE CONTROLE, POTSDAMER PLATZ, CRUZES E CEREJEIRAS}

Além da East Side Gallery, partes do muro que estão preservadas ainda podem ser encontradas em vários outros pontos da cidade. Além dos resquícios evidentes das paredes, podemos encontrar, como nas conhecidas Bernauer Strasse e Potsdamer Platz, espaços aproveitados para preservar torres de controle, totens sonoros, pequenos monumentos e cruzes memoriais.

Esses pontos, além de nos lembrar que o Muro de Berlim foi construído como um sistema de defesa que percorria longas distâncias, como a East Side Gallery, recordam-nos também o uso extensivo de obstáculos como arames farpados, cercas, barras, barreiras de veículos, suportes para fusíveis, torres de controle, trincheiras e tanques de guerra. Por meio de fotos, mapas geográficos, plataformas e instalações de artistas contemporâneos nos são mostradas as várias etapas da construção do muro. No início, tínhamos guardas e arames que logo foram trocados por paredes construídas com elementos de concreto e blocos vazados. Em 1962, percebemos, pelos registros, que o chamado "muro interior" já tinha sido adicionado. Em 1965, os componentes anteriores foram substituídos por blocos de concreto armado ou com aço embutido. Na sua parte superior foi colocada, ainda, uma espécie de rolete de concreto que fazia a cobertura da parede e que não permitia o apoio para as mãos daquele que tentasse escalá-lo. Finalmente, em 1975, o "Grenzmauer 75" foi usado como o tipo da "terceira geração" do muro e gradualmente 
substituiu a construção anterior. O muro de concreto era pré-fabricado e podia atingir cerca de 3,75 metros de altura. A nova configuração era de mais fácil utilização e mais resistente às influências externas e à degradação ambiental.

Esses locais de memória demostram como o sistema de defesa entre os dois países era constantemente expandido, registrando para os visitantes até as demolições de casas que estariam no trajeto do muro e cujos moradores eram realocados à força. Um desses pontos nos mostra que a Igreja da Reconciliação foi implodida, na Bernauer Strasse, para que se continuasse a abertura do espaço interno entre os muros que estavam ali sendo construídos. ${ }^{11} \mathrm{O}$ amplo espaço que fica entra as duas antigas paredes do muro é conhecido pela linguagem atual por "border strip" ou "wall strip". É claramente visível, em parte por grandes áreas como a Bernauer Strasse e entre os distritos de Mitte e Kreuzberg ao longo Kommandantenstrasse, na antiga Jacob Road, Stallschreiberstraße, Alexandrinenstrasse e Sebastianstrasse e em muitos outros lugares. Nas áreas da cidade em crescimento o limite é difícil de identificar. No entanto, toda a brutalidade da divisão pode ser traçada em lugares onde os restos do muro ainda são conservados. Testemunhos importantes são completados por trechos preservados como a Torre de Controle da Erner Berger Strasse, pela região da Potsdamer Platz, nas fotos colocadas na Ponte de Bosebrucke, que lembram exatamente o dia em que a população avançou sobre a fronteira, ou realizando um percurso entre o Portão de Brandenburgo e o Check Point Charlie. ${ }^{12}$

Fica entendido nesses trajetos que, no início, alguns desses lugares eram muito difíceis de serem protegidos devido ao fluxo de pessoas e por causa dos vários espaços vazios surgidos com as demolições recentes ou que não estavam preenchidos desde o final da guerra. Essas áreas eram fechadas e exigiam uma permissão especial para o deslocamento. Isso significava uma restrição severa para a qualidade de vida dos moradores. Como "perímetro de defesa", eram adotadas medidas físicas estruturais (barreiras) ou advertências (luzes, placas, avisos sonoros) para pessoas não autorizadas que se aventurassem por essas áreas. Com o tempo, o espaço interno que ali se configurava consistia em uma estrada aberta entre dois muros contínuos com torres de vigia, iluminação noturna e circulação de cães que rasgava o interior de uma cidade densamente povoada. Algumas cifras apontam quase mil cães em serviço de guarda nesse espaço e que foram usados até o início dos anos 80. As torres de vigia, por sua vez, possuíam holofotes para contato visual entre os postos mesmo durante o dia.

\footnotetext{
${ }^{11} \mathrm{O}$ memorial surgiu de uma consulta patrocinada pelo governo federal em 1994 e foi inaugurado após longas e acaloradas discussões em 13 de agosto de 1998. Ele representa uma seção de parede recém-construída no local original, complementada por meios artísticos e criativos. O centro de documentação, que é apoiado por uma associação, foi aberto em 9 de novembro de 1999. Em 2003, foi complementado por uma torre de vigia, da qual as paredes do memorial são claramente visíveis. Além das constantes exposições, existem diferentes opções de informações sobre a história do muro. Além disso, seminários e outros eventos são oferecidos nessas instalações. A Capela da Reconciliação, da Comunidade de Reconciliação Evangélica, foi inaugurada em 9 de novembro de 2000. O edifício é uma construção de terra batida oval e foi construído sobre as fundações do coro da Igreja da Reconciliação que foi implodida em 1985.

${ }^{12}$ Reforçando esse discurso, o History Mile do Muro de Berlim é uma exposição permanente em quatro idiomas, composta por 21 painéis informativos. Estes são distribuídos nos limites do centro da cidade e contêm fotografias e textos sobre eventos que ocorreram no local dos painéis. Referem-se, por exemplo, às fugas bem-sucedidas ou aquelas que falharam.
}

Revista Lumen, v. 4, no 7, Jan./Jun. - 2019- ISSN: 2447-8717 
Essas construções na fronteira entre as duas cidades eram tratadas como um segredo militar e, portanto, não eram conhecidas exatamente pela maioria dos cidadãos da RDA. Os guardas da fronteira eram obrigados a ficar em silêncio. Todos os civis que mostravam interesses pelo assunto, ou pelo que era construído, corriam o risco de serem levados em custódia para averiguação no departamento de polícia mais próximo ou para o comando da fronteira. Uma sentença de prisão poderia ser executada em caso de desconfiança de planejamento ou tentativa de fuga para o lado ocidental.

Após a queda do muro, alguns trechos da antiga parede continuam ainda a ser declarados monumentos nacionais. Um trecho de cerca de 200 metros, interrompido apenas por uma pequena lacuna, encontrado na Niederkirchnerstrasse e vizinho ao Ministério Federal das Finanças, é um desses exemplos. Também em meados de 1990, a pedido do Ministério Federal dos Transportes, Construção e Desenvolvimento Urbano, foi desenhado um longo muro que se afunda em uma poça de água para lembrar os trechos que não estavam mais ali ao lado da Gnadenkirche. Christoph Girot, arquiteto paisagista, foi encarregado dessa obra.

Continuando as disputas sobre a maneira de recordar esse passado, o debate público esquentou com a criação dos pontos de Checkpoint Charlie e o Liberty Memorial. O governo de Berlim teve que responder à acusação de que não teria um conceito real de memória ao convocar a comissão para as celebrações da primavera de 2005. A partir do ano seguinte, o governo local insistiu, então, em um modelo que fosse integrado à extensão do memorial da Bernauer Strasse. Esse trecho do memorial do Muro de Berlim, já citado aqui, existe naquele espaço desde 1998 e compreende uma seção preservada das fortificações fronteiriças, o Centro de Documentação do Muro de Berlim e a Capela da Reconciliação que lembra a igreja implodida. Esse complexo sobre a Memória do Muro de Berlim, projetado por Thomas Flierl, planeja ainda expandir o memorial em Bernauer Strasse e incluir parte da antiga estação ferroviária de Szczecin na Gartenstraße.

Ao longo da faixa de terra ao redor de toda a antiga Berlim Ocidental, fica ainda outra parte da rota do Muro de Berlim, cujo estabelecimento pelo governo da cidade se deu em 11 de outubro de 2001. A trilha, ao longo da rota de 160 quilômetros das antigas fortificações fronteiriças, está principalmente bem desenvolvida e quase completa desde 2005. Exceto em trechos menores, a rota está toda pavimentada. Essa trilha marca o curso das antigas fortificações fronteiriças da RDA para Berlim Ocidental. Leva cerca de 160 quilômetros ao redor da antiga metade da cidade. Seções historicamente interessantes, onde permanecem fragmentos do muro ou traços da alvenaria de antigas construções, podem ser encontradas. A trilha está sinalizada e equipada com mapas de orientação em intervalos regulares para orientação. Infostones com fotografias e textos fornecem informações multilíngues sobre a divisão da Alemanha e do Muro de Berlim, e retratam eventos no respectivo local ou apontam remanescentes de muros no local.

Das antigas 302 torres de guarda de fronteira, cinco ainda estão de pé hoje. Uma delas é o antigo posto de comando Kieler Eck na Kieler Strasse em Mitte, perto do Canal Berlim-Spandau. A torre está rodeada agora por edifícios novos. Abriga um memorial em homenagem a uma das vítimas do muro, Günter 
Litfin, que foi morto a tiros em agosto de $1961 \mathrm{em}$ Humboldthafen. O memorial é mantido por iniciativa do seu irmão: Jürgen Liftin.

No campo das manifestações artísticas e culturais, o muro está presente desde sempre. $\mathrm{O}$ artista berlinense Stephan Elsner, em 1982, aproveitou uma peça do Muro de Berlim e realizou uma pintura inovadora em uma obra com cerca de oito metros quadrados. Essa ação foi conhecida como, em tradução livre, "A Violência da Fronteira na Faixa da Morte". Em 1984, Claus Hebell criou uma sinopse de todos os slogans do Muro por meio de um passeio de bicicleta sob o título "Conditio Humana" para a revista Cultural Kultuhr. Em 1989, o artista Wolf Vostell criou uma pintura intitulada 9 de novembro de 1989 e, em 1990, um ciclo de pinturas intitulado A Queda do Muro de Berlim.

Por ocasião da queda do Muro de Berlim, o Grupo TV Asahi organizou uma campanha de arrecadação de fundos para a Sakura no Japão com o objetivo de embelezar a faixa de fronteira com uma avenida de cerejeiras. Esta ação reuniu cerca de dois milhões de marcos a partir dos quais cerca de 10 mil cerejeiras ornamentais foram plantadas em Berlim e Brandenburgo. Milhares delas estão localizadas na antiga faixa de fronteira perto de Teltow-Sigridshorst, onde um festival para as flores das cerejeiras é realizado anualmente desde 2002.

Em 21 de julho de 1990, Roger Waters apresentou, em Potsdamer Platz, no trecho do muro que tinha acabado de cair, o álbum lançado em 1979, The Wall, da banda de rock Pink Floyd. O álbum fala sobre uma parede psicológica que originalmente não tinha nada a ver com o Muro de Berlim. No entanto, pelo contexto midiático da época, foi estabelecida uma comparação como o contexto histórico vivido, que foi bem muito bem recebido pelos fãs e pelo mercado cultural.

De qualquer forma, podemos perceber que, para lembrar essas vítimas, nesses espaços aos quais estamos nos referindo, foram erguidos memoriais muito diferentes com manifestações também diferentes. Como exemplo, temos ainda cruzes menores, ou outros sinais de lembrança, que aparecem e servem constantemente para lembrar os fugitivos que foram baleados. Elas estão localizadas em diferentes partes da antiga fronteira e contam, principalmente, com a iniciativa privada. Um memorial bem conhecido são as cruzes brancas próximas ao edifício do Reichstag.

\section{CHECKPOINT CHARLIE E MAUERMUSEUM}

O Checkpoint Charlie foi uma das passagens de fronteira entre Berlim Ocidental e Berlim Oriental durante a existência do Muro de Berlim (1961-1989). O posto de controle foi estabelecido para averiguar as viagens pela fronteira e para contatos entre militares ocidentais aliados, a Associação Militar Soviética (SMM) e os diplomatas estrangeiros. O posto de fronteira foi autorizado a ser usado apenas por militares aliados e membros de embaixadas, estrangeiros e colaboradores de representação permanente da República Federal da Alemanha com a RDA. Ele foi um dos três pontos de controle dos aliados 
usados pelos norte-americanos e recebeu o nome da terceira letra de acordo com o Alfabeto Ortográfico Internacional (Alpha, Bravo, Charlie, ...).

Neste exato ponto geográfico, tanques soviéticos e americanos ficaram frente a frente e prontos para lutar em 27 de outubro de 1961. O incidente se deve à tentativa, por parte do bloco socialista, de restringir os direitos dos aliados e das potências ocidentais sobre Berlim. Hoje se sabe que os comandantes dos dois lados, se necessário, tinham ordens para usar seus tanques. Esse posto de controle também foi palco de fugas espetaculares provenientes da Alemanha Oriental. Aí aconteceu a morte do refugiado Peter Fechter que sangrou até a morte diante dos olhos dos observadores ocidentais. Em 1974, o policial Burkhard Niering levou um inspetor de passaportes como refém e foi baleado durante a tentativa de fuga. Em 1986, três cidadãos da RDA conseguiram romper as barreiras da fronteira com um caminhão de pedras. Em 1989, outro refugiado passou pela fronteira com sua filha no porta-malas de um veículo ocidental.

O posto de controle já tinha se transformado em um memorial mesmo antes da reunificação alemã. Uma réplica fiel do primeiro quartel de controle foi instalada no local desde 2000. Os sacos de areia empilhados foram preenchidos com concreto em vez de areia. O local do antigo Checkpoint Charlie é hoje um dos locais mais famosos de Berlim e abriga, ao mesmo tempo, o Mauermuseum.

O Mauermuseum foi aberto em 1963 por Rainer Hildebrandt que era historiador, autor e combatente da resistência contra o Nacional Socialismo. O museu documenta a história e os eventos ligados ao muro, as fugas e a luta não violenta pelos direitos humanos. O museu ilustra a instalação da fronteira, a "assistência dos poderes de proteção" e o constante aperfeiçoamento do controle. Informa sobre os eventos no antigo posto fronteiriço e aborda a importância do Checkpoint Charlie como um lugar simbólico no confronto internacional dos blocos capitalista e socialista. Entre outras coisas, mostra cenas do dia em que os tanques soviéticos e americanos quase se enfrentaram. Além de fotos e documentações de tentativas bem sucedidas de fuga, também mostra os meios para isso: balões de ar quente, carros, teleféricos e um minissubmarino. Nesse sentido, segundo Daniela Coelho:

Ao abraçar sua vocação social e política, o museu se transforma numa ferramenta importante de promoção dos direitos humanos, do exercício da cidadania e da dignidade humana ao promover o reconhecimento e valorização de identidades culturais e memórias de comunidades locais, aproximando o homem de seu patrimônio; ao permitir ao homem se expressar criativamente; ao proporcionar um espaço para reflexões e debates sobre temas relacionados a diferenças, justiça e igualdade; ao promover a inclusão de públicos esquecidos (...), buscando reduzir as desigualdades de participação social; ao promover a emancipação a partir da democratização de acesso ao conhecimento e formação de sujeitos críticos; ao celebrar a diversidade, procurando contribuir para a coesão social de comunidades; etc. (COELHO, 2015, p.56).

A equipe do museu participa também de pesquisas sobre pessoas desaparecidas na zona de ocupação soviética. Em cooperação com a Cruz Vermelha Alemã, muitos casos não resolvidos estão sendo reabertos. O Museu do Muro também faz parte, por exemplo, de uma campanha mundial para 
esclarecer o destino de Raoul Wallenberg, que salvou centenas de milhares de judeus húngaros dos nazistas e depois desapareceu. Em um passado recente, o trabalho de pesquisa do museu levou à libertação de Mikhail Khodorkovsky.

\section{MUSEU JUDAICO DE BERLIM}

O Museu Judaico de Berlim é o maior museu de cultura judaica da Europa e apresenta uma exposição constante sobre quase dois milênios da história judaico-alemã, incluindo os altos e baixos das relações entre judeus e não-judeus. O museu que está em Lindenstraße 9-14, no bairro berlinense de Kreuzberg, abrange o antigo prédio barroco do Kollegienhaus (antigo Superior Tribunal) e o edifício contemporâneo em zig-zag do arquiteto norte-americano Daniel Libeskind. No lado oposto da Lindenstrasse estão as outras partes do Museu Judaico que foram construídas em 2011 no antigo mercado de flores, também de acordo com um projeto de Libeskind. Lá estão o arquivo, a biblioteca, a parte educativa, o jardim da diáspora e um salão de eventos. Desde a sua inauguração, em 2001, é um dos museus mais visitados na Alemanha. ${ }^{13}$

Em 24 de janeiro de 1933, seis dias antes da "tomada do poder" pelo regime nazista, tinha sido inaugurado o primeiro Museu Judaico de Berlim. Seria, em sua época, o primeiro Museu Judaico do mundo com obras de arte, documentos históricos relativos ao passado judaico e arte modernista judaica. A coleção de arte era entendida como uma contribuição para a história da arte alemã. Em 10 de novembro de 1938 (durante os pogroms de novembro), o museu foi fechado pela polícia secreta do estado e o inventário do museu foi confiscado. Hoje, partes dessa coleção de arte estão localizadas no Centro Cultural Skirball em Los Angeles e no Museu de Israel em Jerusalém.

Em 1971, durante as comemorações sobre a longa duração e a permanência da comunidade judaica em Berlim, nasceu a ideia de uma nova fundação para o antigo museu. Em 1989, Daniel Libeskind ganhou o primeiro prêmio em um concurso que pensava a ampliação do museu na cidade. ${ }^{14} \mathrm{~A}$ partir desse momento, ocorreram muitas discussões e um debate acalorado dentro da comunidade judaica. Em 1994, Amnon Barzel foi nomeado diretor do Museu Judaico, que inicialmente era apenas parte do Museu de Berlim. Ele fez campanha por sua independência legal. Em dezembro de 1997, foi sucedido por W. Michael Blumenthal, que também insistiu em fundar um museu judeu independente. O Museu Judaico foi fundado, então, em 1999, como uma instituição do Estado e do governo. Já nessa época, mesmo estando vazio, o novo prédio estava aberto aos visitantes. O museu foi aberto ao público em 13 de setembro de 2001.

\footnotetext{
${ }^{13}$ COELHO, 2015, p.117-126.

14 A pedra fundamental para o novo edifício foi colocada em 1992.
} 
A exposição permanente, sujeita a transformações durante o tempo de existência do museu, sempre é apresentada pelos olhos da minoria judaica. Retrata os assentamentos medievais ao longo do Reno, legados intelectuais e pessoais de personalidades dos séculos XVII e XVIII, a convivência no século XIX e os desafios de soldados judeus alemães lutando pelo país na Primeira Guerra Mundial e no início do século XX. A exposição pensa, principalmente, como judeus que viveram na cidade (comerciantes e empresários, cientistas e artistas) foram pioneiros e ajudaram na criação de uma importante metrópole europeia. Na seção sobre o nacional-socialismo, é mostrada a crescente discriminação e a busca por escolas e serviços sociais judaicos. Após a II Guerra Mundial são relatadas as histórias dos sobreviventes que esperavam uma possibilidade de imigrar e a formação de pequenas comunidades judaicas no oeste e no leste. No final da exposição, são examinados dois grandes julgamentos nazistas do período pós-guerra: o julgamento de Frankfurt-Auschwitz (1963-1965) e o julgamento de Majdanek em Dusseldorf (1975-1981).

As coleções do Museu Judaico datam desde a década de 1970 e formaram-se com a ajuda e o trabalho da associação que pensava a formação da instituição. As primeiras aquisições foram obras de arte judaica e obras cerimoniais que, aos poucos, foram aumentadas por fotografias e objetos de memória familiar.

O museu é o próprio resultado estético da Berlim após a II Guerra Mundial. Tendo seu patrimônio arrasado, recorre muitas vezes às reconstruções de casas e edifícios. Esse expediente sempre está sujeito a muita discussão e controvérsia. A discussão principal é a falsidade daquela arquitetura enquanto testemunho da história, já que não presenciou os fatos que agora quer ser lembrança. ${ }^{15}$ Nesse caso, contamos com a reconstrução do exterior de um edifício barroco que é acoplado, pelo subterrâneo, ao prédio de linhas contemporâneas que pretende também, por sua forma angulosa, ser um testemunho da história. Nesse caso, o prédio contemporâneo em forma de raio é o próprio intérprete do passado do povo judeu. Salas com ângulos diferenciados, passagens largas e estreitas, salas com pequenas janelas ou espaços com o pé-direito infinito podem causar uma sensação de vertigem ou claustrofobia. A própria trajetória do povo judeu na Alemanha do século XX está vivenciada nos ângulos formados pelas paredes internas do edifício. Em um dos espaços, o visitante pode pisar centenas de chapas redondas de metal que lembram rostos humanos por apresentarem "olhos" e "boca". O próprio barulho metálico do peso dos pés sobre as chapas e, por consequência, das chapas sobre as chapas, traz o absurdo da experiência de uma sociedade que matou milhões de pessoas de forma industrializada.

\section{MEMORIAL DO HOLOCAUSTO}

${ }^{15}$ BRANDI, 2008. p.113-120. 
O Memorial aos Judeus Assassinados da Europa, ou Memorial do Holocausto, guarda a lembrança dos milhões de judeus que foram assassinados sob o domínio de Adolf Hitler e do NacionalSocialismo. O memorial, projetado por Peter Eisenman, consiste de 2.711 estelas de concreto cuboide em uma área de cerca de $19.000 \mathrm{~m}^{2}$ ao sul do Portão de Brandemburgo. Uma exposição memorial subterrânea de $930 \mathrm{~m}^{2}$ (local de informação) completa o complexo. O monumento foi construído durante os anos de 2003 e 2005, tendo uma grande repercussão na mídia e no público. ${ }^{16}$

Os pilares foram dispostos em fileiras paralelas em um terreno de superfície irregular. Por isso, os próprios pilares apresentam certo grau de inclinação em relação ao solo, dando a impressão de um grande cemitério de lápides antigas. O espaço entre as lápides é uniforme e possibilita a existência de caminhos que são totalmente acessíveis aos visitantes, mas não fornecem espaço suficiente para ficarem lado a lado em pares. A parte subterrânea é composta por quatro salas de exposição, duas salas de leitura e uma livraria. Nas estações de computadores, cerca de quatro milhões de nomes de vítimas do Holocausto podem ser acessados.

A área que compreende o memorial pertencia ao antigo espaço dos jardins ministeriais antes da Segunda Guerra Mundial. Nos terrenos ficava a casa de Joseph Goebbel e seu bunker, que serviu como posto de comando da Divisão SS "Nordland" na Batalha de Berlim. Este último veio à luz durante a construção do monumento e foi fechado após a total documentação do solo. Entre 1961 e 1989, o local estava localizado na faixa de terra conhecida por "faixa da morte" e fazia parte da segurança da fronteira.

Em 1988, a jornalista Lea Rosh incentivou a construção do monumento. O historiador Eberhard Jäckel apresentou a sua ideia durante uma visita conjunta ao Memorial do Holocausto de Israel, Yad Vashem. Um grupo de apoio foi fundado e a proposta foi cada vez mais apoiada, também na forma de doações.

Em maio de 1994, foi anunciado um concurso, apoiado pela cidade de Berlim, pela República Federal da Alemanha e pelo Förderkreis, no qual foram apresentadas 528 obras. O júri, presidido por Walter Jens, não tomou nenhuma decisão clara, mas concedeu os dois primeiros prêmios aos projetos de Simon Ungers e a um grupo de artistas de Christine Jackob-Marks. Os representantes do país, da federação e do círculo de apoio finalmente favoreceram o projeto de Jackob-Marks: um nível de concreto inclinado de $20.000 \mathrm{~m}^{2}$ com os nomes das vítimas gravados neles. Contudo, o chanceler Helmut Kohl rejeitou o esboço em junho de 1995.

Em 1997, planeamentos de 25 arquitetos e escultores foram novamente recebidos para o projeto que não deveria ter agora o caráter de um memorial único e central. $\mathrm{Na}$ descrição que o regulamentava constava a ressalva: o monumento não poderia e não deveria ser apenas mais um memorial, mas deveria ser uma obra que chamaria a atenção também para os locais históricos onde os crimes nazistas foram

${ }^{16}$ COELHO, 2015, p.110-116. 
pensados. A intenção era provocar a atenção adicional do público para os memoriais já existentes. Mesmo assim, guardaria a comparação e a função de um memorial - já que manteria a tarefa de informação e documentação. O monumento e o local da lembrança estariam direcionados, assim, para a receptividade contemplativa e emocional do visitante.

Muitos debates se travaram a partir desse momento. O comitê de pesquisa expressou seu apoio à proposta de criação de um campo de estelas realizada pelo arquiteto Peter Eisenman e pelo escultor Richard Serra de Nova York. Ainda foram levados em consideração o projeto de Gesine Weinmiller e um esboço de Jochen Gerz e Daniel Libeskind. Enquanto Lea Rosh e outros participantes da escolha tendiam para o projeto de Libeskind, o chanceler Kohl fazia sua opção para o projeto Eisenman / Serra, sugerindo, no entanto, uma revisão: o monumento deveria ser cercado por um cinturão verde, as estelas deveriam ter uma distância maior e inscrições deveriam ser feitas. Michael Naumann, futuro ministro da cultura, apresentou ainda uma visão crítica do projeto e revelou sua contraproposta que incluía a criação de um museu. A iniciadora do memorial, Lea Rosh, teve várias controvérsias com vários representantes judeus que criticavam seus planos.

Em 25 de junho de 1999, o Bundestag alemão debateu em detalhes a construção do monumento. Pedidos para a utilização dos fundos para a construção de uma universidade judaica em Berlim não encontrou maioria. A proposta de Richard Schröder, sobre a construção de um memorial que também lembrasse todas as vítimas do domínio nazista, também foi rejeitado. Finalmente, a construção do monumento foi escolhida a partir de modificações do desenho de Eisenman que incluíam um trecho subterrâneo. Em 2000, o Memorial do Yad Vashem de Israel ofereceu-se para fornecer uma lista de todos os nomes conhecidos de vítimas judaicas do Holocausto.

No projeto original de Eisenman / Serra, as estelas não eram símbolos temáticos, mas sim um campo individual de experiência que criava uma "zona de instabilidade". O próprio idealizador do projeto diz sobre a impossibilidade de representar os horrores do Holocausto por meios tradicionais. Ele estava tentando desenvolver uma nova maneira de representar a memória, quase um lugar sem sentido. Aos poucos, o debate foi aumentando, ganhando a vida pública e novos conteúdos interpretativos foram aparecendo. Pessoas se lembravam de túmulos e sarcófagos, outros indicavam as estelas como cenotáfios e comparavam-nas a memoriais de guerra e cemitérios militares. Alguns falavam também sobre a necessidade desse memorial, lembrando que a maioria dos judeus mortos não tiveram uma lápide ou um túmulo. As críticas também vieram e partiram daqueles que consideravam a necessidade de lembrar todas as vítimas do nazismo e não apenas os judeus. Reclamavam a necessidade de construir outros monumentos para grupos de vítimas que também morreram no Holocausto. ${ }^{17}$

17 YAMAMOTO, 2014. p.44. 


\section{PEDRAS DE TROPEÇO}

As pedras de tropeço pertencem a um projeto do artista Gunter Demnig que começou em 1992. Com pequenas placas comemorativas enterradas no chão, o destino daqueles que foram perseguidos, assassinados, deportados, expulsos ou levados ao suicídio durante o período nacional-socialista está sendo lembrado. Os "pequenos painéis" de latão quadrado, com cantos e bordas arredondados, são rotulados com letras estampadas à mão e apoiados por um cubo de concreto fundido. O texto gravado geralmente começa com "Aqui viveu ...", seguido do nome da vítima e do ano de nascimento. Apresenta, muitas vezes, o ano de deportação e o local da morte. Em alguns casos, o texto também começa com

"Aqui trabalhou ...", "Aqui estudou", etc. Geralmente são inseridos em frente às últimas residências habitadas pelas vítimas e colocados no mesmo nível do pavimento ou da respectiva calçada.

Inicialmente, era apenas um conceito teórico; no entanto, incentivado por um religioso de Colônia, Demnig começou a enterrar pedras de modo a deixar uma marca. Demnig foi julgado pelas autoridades por não ter permissão do poder público da cidade para realizar isso. Ele participou de uma exposição em Berlin-Kreuzberg em 1996 e, mudando-se para a cidade, colocou mais de 50 pedras sem a aprovação oficial. Em 1997, pela primeira vez com uma aprovação oficial, coloca duas pedras a convite de Andreas Maislinger. Friedrich Amerhauser foi o primeiro prefeito a dar permissão a Gunter Demnig para colocar oficialmente pedras de tropeço. A partir disso, desenvolveu-se uma série de ações que levaram à criação do maior "memorial descentralizado" do mundo.

Entre outras coisas, a intencionalidade de Demnig é devolver os nomes às vítimas dos nazistas, que foram reduzidas a números nos campos de concentração. A inclinação para ler os textos sobre os obstáculos deve ser uma reverência a elas. Com essas marcas, chama a atenção constantemente para o local onde os crimes ocorreram e para as deportações em massa.

Demnig, por causa disso, é um crítico em relação à criação de memorais únicos e exclusivos que, em sua opinião, não são suficientemente visíveis para o público. Em tais lugares estabelecidos pela memória oficial, uma celebração é estabelecida uma vez por ano por autoridades que estão no cargo naquele momento e que não têm uma relação específica com essa memória. Demmig, ao contrário, pretende trazer os nomes das vítimas de volta aos lugares de suas vidas e ao cotidiano da vida da cidade. Para isso, o artista recebeu a cooperação de várias associações sem fins lucrativos, além de arquivos locais e catálogos de endereços históricos. Um dado importante dessa empreitada é apoio do banco de dados do Yad Vashem em Jerusalém.

A fonte mais importante para os endereços residenciais, bem como detalhes da vida das vítimas, é a documentação referente ao censo de 1939. Se as casas das vítimas não estão mais preservadas, devido, por exemplo, a reorganização da cidade durante a reconstrução, os obstáculos são colocados nos espaços abertos resultantes. As pedras tornam-se propriedade da cidade ou do município após a sua colocação, razão pela qual a aprovação oficial é importante.

Revista Lumen, v. 4, no 7, Jan./Jun. - 2019 - ISSN: 2447-8717 
As pedras de tropeço são financiadas por doações privadas e são realizadas à mão, porque, de acordo com Demnig, contrasta com a destruição fria e impessoal realizada pelas máquinas nos campos de concentração. No começo, ele as elaborava sozinho; no entanto, com a expansão do projeto, recebeu a ajuda do escultor Michael Friedrichs-Friedlaender. Desde 2006, as pedras de tropeço são feitas em sua oficina em Berlim.

O projeto também é alvo de críticas. Uma oponente notória é Charlotte Knobloch que descreveu como "insuportável" ler os nomes de judeus assassinados em pequenos blocos que estão embutidos no chão e que são pisados pelos transeuntes. Opiniões são divergentes também entre os indivíduos da comunidade judaica. Líderes de importantes associações manifestaram-se contra e a favor do projeto. Alguns espaços, a pedido da própria comunidade judaica, rejeitaram inicialmente os pequenos blocos. Acordos foram possibilitados somente após consulta pública e com a permissão dos respectivos proprietários ou parentes das vítimas. Por vezes, proprietários ou inquilinos, cujas propriedades estão envolvidas, também criticam o projeto. As questões envolvem convicções políticas de extrema direita, a descrença no simbolismo dos blocos ou o medo de ataques por extremistas. Há aqueles que temem o prejuízo econômico à propriedade. Atos de vandalismo também são identificados, principalmente por meio de grafites e pichações com linhas políticas e ideológicas determinadas. Blocos são repetidamente arrancados pela cidade e já foram encontrados alguns com os nomes de alemães que haviam morrido durante os ataques aéreos dos Aliados. Podemos encontrar ainda aqueles que prefeririam um memorial tradicional com os nomes de todas as vítimas.

Além dos blocos tradicionais, com apenas um nome, Demnig coloca ocasionalmente outros que rememoram grupos inteiros de vítimas. Já os colocou para evocar pessoas mentalmente doentes que foram deportadas, grupos assassinados, coletivos de trabalho forçado, etc.

Dois dias de lembrança são marcados com mais frequência: 27 de janeiro, que é o Dia Internacional em Memória das Vítimas do Holocausto, e 9 de novembro, que é o dia da lembrança dos pogroms de 1938. Nesses dias, os blocos são limpos e recebem velas acesas em memória das pessoas assassinadas ou exiladas pelo regime nazista. Os blocos não estão sendo utilizados apenas na Alemanha, mas também em vários outros países, e são considerados o maior memorial descentralizado do mundo, recebendo vários prêmios desde então.

\section{A SINAGOGA EM ORANIENBURGER STRASSE}

A sinagoga em Oranienburger Strasse, que está no subúrbio de Spandau, é um edifício de grande importância para a história da população judaica da cidade e um importante monumento arquitetônico. Foi inaugurada em 1866 e foi reaberta após a restauração de 1995. Os arquitetos foram Eduard Knoblauch e Friedrich August Stüler. 
$\mathrm{Na}$ época, os antissemitas acharam uma provocação aquele magnífico edifício com a cúpula dourada. A construção também desencadeou discussões acaloradas entre a população judaica. Os judeus liberais objetaram que o estilo arquitetônico mourisco não era familiar e enfatizava a estranheza da religião judaica, impedindo assim o processo de integração desejado. Judeus conservadores apresentaram suas reservas e falaram contra as várias inovações no culto e no estilo dos salões interiores. A maioria, no entanto, entendeu o edifício com orgulho e como um símbolo da importância e da autoconfiança da comunidade judaica em Berlim. O maior, mais caro e magnífico templo judaico da Alemanha também era exemplo da aplicação das mais modernas técnicas de construção, tornando-se uma atração muito notada.

Durante os pogroms que ocorriam em todo o país, especialmente na noite de 9 de novembro de 1938, membros da SA começaram a atear fogo à sinagoga. As forças públicas confrontaram os incendiários e conseguiram preservar o edifício, chamando os bombeiros. Krützfeld, autoridade que havia agido de acordo com os regulamentos e atendido ao chamado para controlar a situação da sinagoga, foi então exposto em seu cargo e passou a sofrer assédio. Uma placa comemora a sua ação e lembra sua atuação corajosa naquele ambiente hostil de difícil situação política. O edifício foi utilizado até 14 de janeiro de 1943 quando ocorreu o último culto em uma sala do interior. A cúpula teve que ser pintada com tinta de camuflagem por causa dos ataques aéreos e a Wehrmacht assumiu o prédio como um acampamento. A sinagoga sofreu danos pesados durante os ataques aéreos britânicos. Os danos continuaram quando, com o fim da guerra, a ruína era usada como fornecedora de materiais de construção.

Depois da guerra, os poucos judeus sobreviventes da cidade fundaram uma nova comunidade judaica baseada no prédio administrativo da sinagoga em Oranienburger Straße. Em primeiro lugar, tratava-se de criar condições adequadas para a vida judaica em Berlim e, por outro lado, preparar a emigração para aqueles que não queriam ficar. No verão de 1958, o prédio parcialmente destruído que ficava em Berlim Oriental teve suas partes danificadas eliminadas devido ao risco de desabamento e em virtude do argumento que afirmava a impossibilidade de uma reconstrução. Apenas os edifícios localizados logo na via permaneceram e foram preservados como um memorial contra a guerra e o fascismo.

Em 1988, a partir das cerimônias que lembravam a Noite dos Cristais, foi fundada uma associação com o objetivo de reconstruir a sinagoga e criar um centro para o cuidado e preservação da cultura judaica. A nova atmosfera vinha ao encontro do apoio à vida comunitária que a política da Alemanha Oriental adotava naquele momento.

Em 10 de novembro desse mesmo ano, foi colocada uma pedra fundamental como um ato simbólico que instigava todos à reconstrução da ruína. Nesse momento, o tipo de restauração já se fazia controverso. Uma restauração completa de seu estado original foi descartada por ter sido entendida como 
uma tentativa de reprimir, e possivelmente esquecer, os sofrimentos do passado. A intenção, no entanto, era preservar o edifício como um local destinado à memória. ${ }^{18}$

Os participantes da iniciativa decidiram então tornar visíveis a arquitetura outrora magnífica e a destruição violenta pela qual o edifício passou. A cúpula principal foi reconstruída fiel ao original e alguns fragmentos das suas ruínas ficaram visíveis no interior. A linha da antiga sinagoga está assinalada no espaço aberto pelas pedras do edifício. O trabalho de renovação foi concluído em 1993 e uma exposição permanente informa sobre a vida judaica em Berlim. Nas imediações existem instalações comunitárias judaicas, restaurantes, cafés e uma galeria.

\section{DDR MUSEUM}

O Museu DDR trata a vida e a cultura cotidiana da RDA em sua exposição permanente. O projeto do museu foi iniciado pelo etnologista Peter Kenzelmann que, de acordo com entrevistas dadas em diversos meios de comunicação, não havia encontrado nenhum museu dedicado à antiga Alemanha Oriental em seus caminhos pela cidade. A casa foi inaugurada em 2006 e tornou-se referência para os pesquisadores do assunto. O museu é uma iniciativa privada e abstém-se do financiamento estatal.

Os espaços introduzem o visitante na vida cotidiana da RDA. Um conjunto habitacional em pequena escala é dividido em seções temáticas como consumo, esporte, música, férias, entre outras. Muitas exibições expostas podem ser tocadas. Além disso, existe uma simulação de condução do clássico automóvel Trabant por meio da qual os visitantes são conduzidos através de um conjunto habitacional virtual. Um jardim de infância, um cinema e estações de áudio também estão na exposição. Nesse caso, o museu:

Oferece a quem o visita a possibilidade de regular, à sua vontade, o ritmo de assimilação [...] dá tempo para reflexão, crítica e deleite. [...] o Museu não pode prescindir do texto e pode utilizar outros procedimentos para melhor cumprir sua missão [...] a exploração dos recursos disponíveis." (RIVIÈRE, G. H., 1958, p. 29).

O museu abrange ainda os seguintes temas: fronteira entre as Alemanhas, Berlim Oriental, tráfego, o muro, a polícia secreta, o consumo, produtos da RDA, família, vida privada, mídia, literatura, educação, infância, juventude, trabalho, moda, cultura, lazer e ideologia. Em contraste com outros museus, uma grande parte das exposições pode ser tocada durante a exposição. $\mathrm{O}$ visitante pode andar pelo apartamento pré-fabricado, mexer nos armários ou experimentar as roupas do guarda-roupa com um espelho digital. Há, também, uma sala de interrogatório reconstruída, uma cela de detenção e uma sala de informadores que fornecia dados sobre o trabalho da segurança do Estado.

${ }^{18}$ CURY, 2004. p.13. 
A coleta e preservação do patrimônio cultural da antiga Alemanha Oriental é uma das principais tarefas do museu. De acordo com dados próprios, a coleção contém milhares de objetos diferentes que são acomodados em uma grande reserva técnica. Os pesquisadores do museu trabalham há anos na coleta de material. Em geral, a exposição não se concentra necessariamente nos objetos individuais, mas na composição cênica onde eles estão alocados. Isso transmite uma experiência moderna e diferenciada ao visitante.

\section{O PALÁCIO DE BERLIM E HUMBOLDT FORUM}

O Palácio de Berlim, também conhecido como o Palácio da Cidade de Berlim, era o edifício predominante do centro histórico da cidade. O palácio da residência dos Hohenzollern foi construído em 1442 e ganhou feições barrocas no século XVIII. Sob o eleito Friedrich III (rei Frederico I na Prússia), veio a expansão da edificação para criar uma ambientação apropriada a uma residência real. O modelo do projeto foi a fachada do Palazzo Madama em Roma. Tornou-se, por isso, um significativo edifício secular do Barroco Protestante. A partir de 1871, tornou-se a residência sede do Império Alemão. O palácio estava ao final da avenida Unter den Linden como um importante edifício barroco e como o maior edifício do centro da cidade. Várias ruas foram alinhadas a ele, de acordo com o plano urbanístico, o que resultaria num conjunto urbano representativo que levava em consideração o tamanho das construções nas imediações, a proporção e a orientação delas para o palácio. ${ }^{19}$

O edifício foi gravemente danificado e parcialmente queimado durante a Segunda Guerra Mundial, mas ainda poderia ser reconstruído a partir do que restou. As paredes externas, juntamente com a decoração escultural, as paredes de sustentação e, em sua maior parte, as escadarias principais, permaneceram intactas. A ala do Salão Branco, ligeiramente danificada, continuou a servir como espaço administrativo.

Em 1949, soldados soviéticos destruíram várias esculturas e peças remanescentes dos vitrais do palácio durante as filmagens de “A Batalha de Berlim”. Em 1950, forças governamentais decidiram pela sua completa remoção e remodelação a fim de criar um local para grandes manifestações e marchas. A decisão pela destruição desse bem cultural único foi criticada por autoridades alemãs e publicamente em todo o mundo.

Sem um planejamento adequado, ou a preparação feita por um grupo de especialistas, foram recuperados cerca de duas mil obras valiosas entre esculturas, objetos decorativos e fragmentos arquitetônicos. Essas ações foram tomadas de maneira a tranquilizar o público, como foi provado por

\footnotetext{
${ }^{19}$ ALMEIDA, 2013, p.70.
} 
documentos em décadas posteriores. Ao final, o processamento científico da documentação não se materializou e as peças obtidas foram negligenciadas em um terreno onde muitas delas se perderam. Outras partes do palácio, que haviam sido recuperadas antes da demolição, foram instaladas em um prédio governamental. Nas décadas seguintes à destruição, qualquer assunto relacionado ao Palácio de Berlim era considerado um tabu dentro da Alemanha Oriental. Os arquivos necessários para a pesquisa científica eram mantidos em sigilo.

Até 1951, a área ficou limpa, nivelada e coberta com lascas de tijolos vermelhos. A praça ampliada recebeu o nome de Marx-Engels-Platz, em homenagem aos teóricos Karl Marx e Friedrich Engels. Os planos desenvolvidos nos anos seguintes para redesenhar o local permaneceram por cumprir durante 20 anos. Além do uso ocasional para eventos, o local permaneceu inexplorado até a década de 1970.

Em 1971, como gesto programático, foi considerada a construção de um edifício polivalente na Marx-Engels-Platz. O Palácio da República, com linhas modernas, concreto e vidro, serviu de sede da Câmara do Povo e foi concluído em 1976. Com a reunificação do país, esse prédio que servia como sede do governo da antiga Alemanha Oriental foi fechado devido à contaminação por amianto e demolido entre 2006 e 2009. A demolição desse novo edifício também não escapou das críticas que afirmavam que a sua real intenção era apagar a memória do Socialismo. ${ }^{20}$

Em junho de 2013 foi colocada uma pedra fundamental na localização original do antigo palácio e, utilizando a fachada reconstruída e partes da antiga construção, um novo edifício começou a ser erguido. A reconstrução das fachadas barrocas foi financiada em grande parte por doações privadas. ${ }^{21}$

Em seu relatório final, uma comissão de especialistas defendeu o conceito do futuro Fórum Humboldt no Palácio de Berlim. Para isso, as coleções de arte não europeia seriam instaladas no palácio reconstruído fazendo alusão a uma Berlim multicultural que guarda consigo uma parte da cultura mundial. A intenção de seu centro de eventos é unir as culturas do mundo e lembrar o passado científico e cultural da cidade. O objetivo é conectar tematicamente as culturas do mundo nos andares superiores com a própria cidade de Berlim, com foco na história internacional da cidade. O palácio complementaria então a região da Ilha dos Museus.

\section{CONSIDERAÇÕES FINAIS}

\footnotetext{
${ }^{20}$ BEUTELSCHMIDT; NOVAK, 2001, p.45.

21 "Berlim, (...) continua a ser um dos principais estaleiros de reconstrução urbanística na Europa, como se pode verificar, por exemplo, com a decisão de demolir o antigo Palácio da República da ex-Berlim Leste ou de desativar o histórico aeroporto de Tempelhof." Cf.. Berlim, a capital que se reconstrói sempre. In Ordem dos Arquitectos. Disponível em: http:/ / arquitectos.pt/?no=2020491355,156. Acesso em: 06 de dezembro de 2008.
} 
Avaliar os danos e as perdas de vidas na história recente de Berlim é quase impossível. As indicações são sempre contraditórias. Sabemos que milhares, ou melhor, milhões de pessoas pereceram após a perseguição aos judeus, socialistas, homossexuais e testemunhas de jeová pelo Nacional Socialismo. Temos os bombardeios ingleses e norte-americanos sobre a população civil alemã durante a guerra e ainda assistimos à invasão da cidade pelos russos e o acerto de contas final em relação às vítimas soviéticas. Na divisão da cidade durante a Guerra Fria, nas tentativas de superar o maior número de quilômetros de extensão e instalações de fronteira fortemente vigiadas em direção à Berlim Ocidental, de acordo com dados de 2009, entre 136 e 245 pessoas foram mortas. O número exato de mortes é desconhecido. A dificuldade de fazer declarações exatas nessa área é também ilustrada pelo número de documentos perdidos, pelos depoimentos contraditórios ou pela inexistência dos registros. Esses são os maiores desafios para aqueles que querem reconstruir a história da cidade e esclarecer a realidade dos fatos.

Nesse sentido, as criações artísticas, as instalações, os museus, os monumentos, as pedras de tropeço e os restos do muro têm sempre o objetivo de identificar e documentar a história das vítimas e tornar público o papel que a Alemanha moderna tem em relação ao presente e às outras potências mundiais: o de se mostrar avançada, democrática, inclusiva e aliada dos antigos inimigos. Arquivos e monumentos são criados constantemente de modo a tornar essas informações acessíveis ao público. Essas medidas são corroboradas pelo tratamento jurídico dado aos algozes sobreviventes do Nacional Socialismo ou das forças de repressão da antiga Alemanha Oriental, que incluem desde o Julgamento de Nuremberg até os recentes julgamentos de líderes militares e importantes homens de Estado da RDA. Mesmo assim, a demarcação das áreas, a construção dos monumentos ou a construção de museus sofrem críticas de diversos grupos. Em muitos momentos, grupos acusam determinados projetos de pesquisa de conscientemente "minimizar" o número de vítimas por razões políticas. Alguns outros acusam os projetos nos quais não há historiadores envolvidos. Esses incidentes servem também para acusar os governos, ou vítimas, de agirem propagandisticamente e como justificativa para aqueles que querem ver esse passado esquecido. Sem contar ainda que, no caso do Muro de Berlim, grandes fragmentos foram usados rapidamente para fins lucrativos como construções em espaços urbanos, vendidos para museus e galerias ao redor do mundo e em pequenos fragmentos como souvenir em forma de chaveiros ou acoplados a cartões postais para turistas.

De qualquer forma, o espaço urbano de Berlim continua sendo uma zona de conflitos. Agora, por aqueles que falam em nome do passado e por aqueles que estão criando a memória desse mesmo passado. Por isso também, a paisagem urbana de Berlim exibe grandes quantidades de arte de rua e na rua. Tornou-se uma parte significativa da herança cultural da cidade e encontrou apoio na cena do grafite de Kreuzberg dos anos 80. O próprio Muro de Berlim tornou-se uma das maiores telas ao ar livre do mundo. 
É muito significativo entender como uma cidade moderna, com edifícios e equipamentos de última geração, consegue, de alguma maneira, dialogar com sua História e colocá-la diante dos transeuntes do presente por meio de instalações, obras de arte e prédios contemporâneos. Berlim não exibe a paisagem histórica que as grandes capitais europeias gostam de exibir e de vender como imagem de propaganda e turismo, mas consegue trazer para o tempo presente aquilo que os bombardeios deixaram para trás. Poderia ser um exemplo interessante para as cidades do Novo Mundo, na América, que vivem sendo reerguidas, destruídas e reconstruídas. A perda da paisagem original não é desculpa para o esquecimento daqueles que participaram da construção dessa mesma sociedade.

\section{REFERÊNCIAS}

ALMEIDA, Roberto Flavio Sant'ana de. Conservação e valores sob a perspectiva do patrimônio na Alemanha: a prática da reconstrução. 2013. Dissertação (Mestrado em Ambiente Construído e Patrimônio Sustentável) - Escola de Arquitetura, Universidade Federal de Minas Gerais, Belo Horizonte, 2013.

ARENDT, Hannah. Origens do Totalitarismo. São Paulo: Companhia das Letras, 1990.

BARROS, Edgard Luiz. A guerra fria. São Paulo: Perspectiva, 1990.

BENJAMIN, Walter. A obra de arte na época de sua reprodutibilidade técnica. Porto Alegre: Zouk, 2012.

BODENSCHATZ, Harald. Berlin urban design: a brief history. Berlim: Dom Publishers, 2010.

BERMAN, Marshall. Tudo que é sólido desmancha no ar : a aventura da modernidade. São Paulo: Companhia das Letras, 1986.

BEUTELSCHMIDT, T.; NOVAK, J. M. Ein Palast und seine Republik, Ort-Architektur-Programm. Berlim, 2001.

BRANDI, Cesare. Teoria da Restauração. 3.ed. Cotia, SP: Ateliê Editorial, 2008.

CASTRIOTA, Leonardo Barci. Patrimônio cultural: conceitos, políticas, instrumentos. São Paulo: Annablume; Belo Horizonte: IEDS, 2009.

CHOAY, Françoise. A alegoria do patrimônio. São Paulo: Editora UNESP. 2000.

COELHO, Daniela Vicedomini. O Musen do Holocausto de Curitiba sob a perspectiva da Museologia Contemporânea. 2015. Dissertação (Mestrado em Museologia) - Faculdade de Ciências Sociais, Educação e Administração, Universidade Lusófona de Humanidades e Tecnologias, Lisboa, 2015.

CURY, Isabelle (org.). Cartas patrimoniais. 3. ed. Brasília: IPHAN, 2004.

FALSER, Michael. Zwischen Identität und Authentiæität. Zur politischen Geschichte der Denkmalpflege in Deutschland. Dresden: Thelem Verlag, 2008.

HOBSBAWN, Erick J. A Era dos Impérios: 1874-1914. Rio de Janeiro: Paz e Terra, 1989.

HOBSBAWN, Erick J. A Era dos Extremos: 1914-1991. São Paulo: Companhia das Letras, 1993.

Revista Lumen, v. 4, no 7, Jan./Jun. - 2019 - ISSN: 2447-8717 
HOLFELDER, Moritz. Palast der Republik: Aufstieg und Fall eines symbolischen Gebäudes. Berlim: Ch. Links Verlag, 2008.

HUYSEN, Andreas. Seduridos pela memória. Rio de Janeiro: Aeroplano, 2000.

KITCHEN, Martin. Um mundo em chamas: uma breve história da Segunda Grande Guerra na Europa e Ásia. Rio de Janeiro: Zahar, 1993.

JUDT, Tony. Pós-Guerra: uma história da Europa desde 1945. Rio de Janeiro. Objetiva, 2008.

JUDT, Tony. Reflexões sobre um século esquecido: 1901 - 2000. Rio de Janeiro: Objetiva, 2011.

LADD, Brian. The Ghosts of Berlin: Confronting german history in the urban landscape. Chicago:

University of Chicago Press, 1998.

MONIZ BANDEIRA, Luiz Alberto. A reunificação da Alemanha: do ideal socialista ao socialismo real. São Paulo: Global, 2001.

RALPH, Stern. Reconstrução crítica. Porto: Circo de Ideias, 2008.

RIEGL, Aloïs. O culto moderno dos monumentos: sua essência e sua gênese. Goiânia: Editora da UCG, 2006. RIVIÈRE, G. H. (1958, setembro). Seminário Regional da UNESCO sobre a função educativa dos museus. Extrato do Documento Final do Evento: Quarta Parte - Conclusões do Seminário. Tradução de Maria Cristina Oliveira Bruno e Maria Pierina Ferreira de Camargo. In Bruno, M. C. O. (Coord.) (2010). O ICOM/Brasil e o pensamento museológico brasileiro: documentos selecionados. (Vol. 2, pp. 28-37). São Paulo: Pinacoteca do Estado: Secretaria de Estado da Cultura: Comitê Brasileiro do Conselho Internacional de Museus.

SEGRILLO, Angelo. O Declínio da URSS: um estudo das causas. Rio de Janeiro: Record, 2000.

Y AMAMOTO, José Carlos Amaral. Entre Eisenman, Berlim e o memorial. 2014. Dissertação (Mestrado em Arquitetura e Urbanismo) - Faculdade de Arquitetura e Urbanismo, Universidade de São Paulo, São Paulo, 2014.

WESSON, Robert G. A Nova Politica Externa dos Estados Unidos. Rio de Janeiro: Zahar, 1978. 